\title{
Cleft lip/palate-deafness-sacral lipoma syndrome
}

INSERM

\section{Source}

INSERM. (1999). Orphanet: an online rare disease and orphan drug data base. Cleft lip/palate-deafness-sacral lipoma syndrome. ORPHA:2003

Cleft lip/palate-deafness-sacral lipoma syndrome is characterised by cleft lip/palate, profound sensorineural deafness, and a sacral lipoma. It has been described in two brothers of Chinese orig in born to non consanguineous parents. Additional findings included appendages on the heel and thigh, or anterior sacral meningocele and dislocated hip. The mode of inheritance is probably autosomal or X-linked recessive. 